$X$-ray phase imaging using simple propagation of a coherent synchrotron radiation beam. J. Phys. D: Appl. Phys.32, A145-A15I (1999a)

Cloetens P., Ludwig W., Baruchel J., Van Dyck D., Van Landuyt J., Guigay J.P., Schlenker M., Holotomography: quantitative phase tomography with micrometer resolution using hard synchrotron radiation $X$-rays, Appl. Phys. Lett. 75, 2912-2914 (1999b)

Contreras L., Turillas X., Vaughan G.B.M., Kvick Å., Rodriguez M.A. Time-resolved XRD study of $T i C-T i B_{2}$ composites obtained by SHS. To be published (2004)

Elliott J.A., Windle A.H., Hobdel J.R., Eeckhaut G., Oldman R.J., Ludwig W., Boller E., Cloetens P., Baruchel J., Foam compression by microtomography, J. Mat. Science, 37, 1547-1555 (2002).

Lauridsen E.M, Juul Jensen D. ,Poulsen H.F. Lienert U., Kinetics of individual grains a during crystallisation. , Scripta Materialia, 43, 5561-566(2000).

Martins R.V, Honkimäki V., Depth resolved investigation of friction stir welds using a novel strain and phase mapping technique, Texture and Microstructure, 35, 145-152(2003).

Morcrette M., Chabre Y., Vaughan G.B.M., Amatucci G., Leriche J.B.,Patoux S., Masquelier C., Tarascon J.M. In situ x-ray diffraction techniques as a powerful tool to study battery electrode materials. Electrochimica Acta, 47, 3137-3149 (2002)

Offerman S.E, van Dijk N.H, Sietsma J., Grigull S., Lauridsen E.M, Margulies L., Poulsen H.F., Rekveldt M.Th., van der Zwaag S. Grain nucleation and growth during phase transformations. Science ,298, 1003-1005(2002).

Rüegsegger P., Koller B.and Müller R,. A microtomographic system for the non destructive evaluation of bone architecture, Calcif. Tiss. Int., 58, 24-29 (1996).

Sasov A. and Van Dyck D., Desk-top microtomography: gateway to the $3 D$ world, European Microscopy and Analysis, pp. 17-19 (1998).

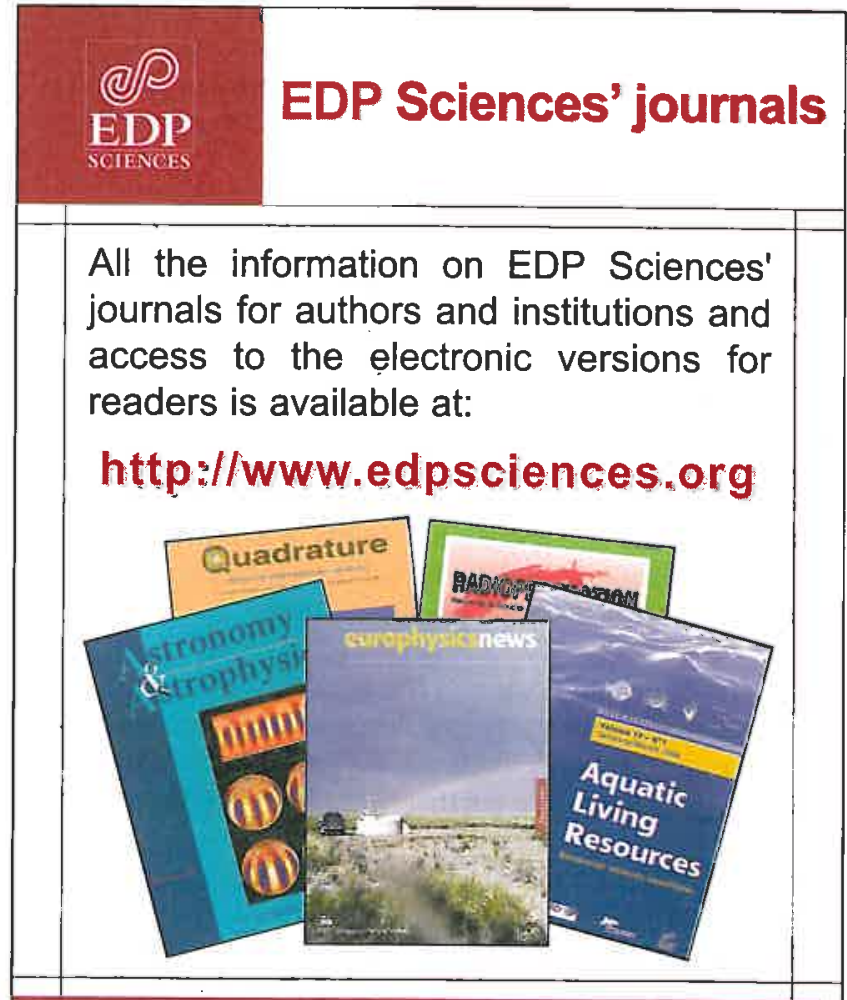

EDP Sciences

17, av du Hoggar - PA. de Courtabœuf

F-91944 Les Ulis Cedex A • France

Tel. $33(0) 169187575$. Fax $33(0) 169860678$

subscribers@edpsciences.org

\section{What is your strategy for Framework 6?}

\author{
Sean McCarthy, Managing Director of Hyperion Ltd.
}

$H$ ow many research organisations have a formal written strategy for Framework 6 ? How many individual researchers have a personal strategy for Framework 6? This article presents a checklist for the writing of a simple but practical strategy for Framework 6.

\section{An organisation's strategy for Framework 6}

The following are examples of statements of objectives that could be used in a research organisation's strategy for Framework 6 . They are based on actual discussions with research organisations on their Framework 6 strategies. (The comments in brackets are actual quotations from research managers)

- To access European Union Funding for research activities. One of the problems with this simple objective is that the researchers may concentrate on obtaining any contracts rather than focussing on the research priorities of the organisation.

- To establish the research group as the European (or International) scientific leader in a scientific area ('to be the best in our field'). It is important that the scientific areas are well defined (a niche within an niche). For example, "to be the world leader in the simulation and design of photovoltaic (solar) systems'.

- To access new technologies relevant to the organisation's areas of excellence ('to avoid missing the train').

- To work with the best research partners in the European Union. ('to be the preferred partner of the best scientists in our field')

- To provide better education and training to graduates and post-graduates. ("We want our graduates to excel in any interview, anywhere in the world')

- To promote the organisation's scientific and technical excellence to the scientific/technical community ('more conferences, more publications, more website hits...')

- To ensure the research results are used by enterprises and society ('getting value from our research efforts')

- To provide relevant support to researchers ('To streamline the process of proposal writing, contract negotiation and contract management/administration').

The strategy should also describe the activities that the organisation will NOT undertake in Framework 6. For example:

- Specific tasks in the contract. (One University clearly informed its researchers that "we will not act as main contractor in Framework 6 contracts').

- No subcontracting. ("We will utilise only internal resources in the contracts')

\section{A strategy for individual researchers}

An individual researcher (or a small research group) should have a strategy covering all of the following issues:

- Which is the scientific niche (or even a 'niche within a niche') where the researcher's expertise is the best and where it complements that of researchers from other research centres. This requires clear identification.

- Which Framework 6 Priorities (sub-programmes) are relevant 
to the researcher? All of the sub-programmes-not just the main programmes-should be identified.

- Which Instruments (types of contracts) will be used? A simple strategy could be the following: ' The research group will focus on Integrated Projects and Networks of Excellence. STREPS will be used to explore future research topics. Specific Support Actions will be used to fund workshops and small conferences. Coordination Actions will be used to fund research networks. Marie Curie Fellowships will be used to hire researchers or to fund $\mathrm{PhD}$ students. The Research Infrastructure instrument will be used to access research facilities'.

- Which 'Calls for Proposal'? Each programme will have (typically) one call for proposals each year. An example of a strategy could be: In 2004 the research group will focus on Specific Support Action to establish links with potential partners. In 2005 the group will set up a Coordination Action to establish a formal network with other research organisations. This network should lead to an Integrated Project or a Network of Excellence in 2006.

- What Role in the Project? Scientific Coordinator? Main contractor? Work-package leader? Consortium Manager? Exploitation Manager?

- Which partners? This is the most critical issue and will require the most thorough analysis. Which companies and in particular which SMEs (Small and Medium Enterprises) could be included in the project? Which partners from the Candidate Countries should be included?

- What support staff is available? Examples include: Who will write the Gender dimension of the proposal? Who will take care of the ethical issues, the consortium agreement etc.?

- Which sources of information? Framework 6 proposals require arguments in science, economic relevance, social relevance, relevance to European Union policies etc. Which are the best sources of information for these sections of the proposal? For this information see www.hyperion.ie/framework6websites.htm

- Which templates can be used to streamline the process of proposal writing? Sample templates can be found on: www.hyperion.ie/templates.htm

\section{From strategy to people}

Framework 6 is about people. It is not just about EU institutions, websites and proposal documents. The researchers who are successful in Framework 6 contracts are active in a wide variety of EU activities. They network and more importantly they maintain networks. The following is a simple strategy for action by a researcher to identify the key individuals in their scientific area in the EU.

1. Identify the relevant individuals in the European Commission. The organisation structure can be found on:

http://europa.eu.int/comm/dgs/research/organisation_en.html

2. Identify the researchers that are already partners in EU R\&D contracts in your area. These can be found on the search engine in http://dbs.cordis.lu/fep/FP5/FP5_PROJ_search.html

3. Identify the individuals that are working as experts to the European Commission. In particular, identify the researchers that are involved in advisory committees or those who write policy documents on scientific topics. Examples of all Framework 6 topics can be found on www.hyperion.ie/fp6websites.htm

4. Join the relevant EU Research Associations. Examples can be found on www.hyperion.ie/euassociations.htm

5. Join relevant Thematic Networks that were funded under Framework 5. These can be found on:

http://dbs.cordis.lu/fep/FP5/FP5_PROJ1_search.html by searching under THEMATIC NETWORK.

6. Researchers should promote their expertise at EU conferences, exhibitions and in relevant magazine. This can be done through Thematic Networks and European Research Associations (listed above).

7. Participate in Framework 6 evaluations to learn the process of proposal writing and proposal evaluation. The call for experts can be found on www.cordis.lu/fp6/

\section{Conclusion}

Strategies are useless pieces of paper unless implemented. A strategy is not a once in a lifetime exercise - it must be regularly updated to reflect changes in internal research priorities, changes in funding rules or changes in funding priorities. It is important that a general strategy exists and that it is communicated throughout the research organisation.

Research organisations and individual researchers should be able to answer the following questions:

- How will the success of participation in Framework 6 be measured?

- How will the failure of involvement in Framework 6 be measured?

- What is the greatest concern of the organisation regarding Framework 6?

- What are the limitations of the researchers and the limitations of the organisation when participating in Framework 6?

If the researchers cannot answer these questions they may be travelling in the wrong direction.

The best strategy will always involve producing the best science and working with the best partners.

\section{About the author}

Dr. Sean McCarthy (sean.mccarthy@hyperion.ie) is Managing Director of Hyperion Ltd. Hyperion specialises in the development of training courses for research managers. Full details of their training courses can be found on www.hyperion.ie. Hyperion's clients can be seen on www.hyperion.ie/clients.htm

\section{Framework 6 proposals feedback}

$\mathrm{H}^{\mathrm{PN}}$ is undertaking a survey to assess the level of involvement of

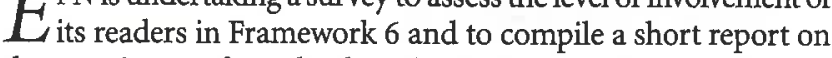
the experiences of people who submitted proposals during the first year of the programme. Sean McCarthy of Hyperion Ltd. will analyse the replies and present the results in a future edition of EPN. This information will be valuable to EPN readers in the planning of future research proposals.

1. Did you submit a proposal to Framework 6?

2. If you did not submit a proposal, then what were your reasons?

3. What was the most difficult part of the proposal to write?

4. Did you participate as a partner or as the coordinator of the proposal?

5. How much effort (in person days) was involved in participating in the proposal?

6. Have you any recommendation you would like to make to the European Commission regarding proposal writing for Framework 6 (and future Framework programmes)?

Please email your replies to sean.mccarthy@hyperion.ie before 28th April 2004. Participation of EPN readers will be greatly appreciated. 